\title{
Local regulation of fat metabolism in peripheral nerves
}

\author{
Mark H.G. Verheijen, ${ }^{1}$ Roman Chrast, ${ }^{1}$ Patrick Burrola, and Greg Lemke ${ }^{2}$ \\ Molecular Neurobiology Laboratory, The Salk Institute, La Jolla, California 92037, USA
}

\begin{abstract}
We comprehensively analyzed gene expression during peripheral nerve development by performing microarray analyses of premyelinating, myelinating, and postmyelinating mouse sciatic nerves, and we generated a database of candidate genes to be tested in mapped peripheral neuropathies. Unexpectedly, we identified a large cluster of genes that are (1) maximally expressed only in the mature nerve, after myelination is complete, and (2) tied to the metabolism of storage (energy) lipids. Many of these late-onset genes are expressed by adipocytes, which we find constitute the bulk of the epineurial compartment of the adult nerve. However, several such genes, including SREBP-1, SREBP-2, and Lpin1, are also expressed in the endoneurium. We find that Lpin1 null mutations lead to lipoatrophy of the epineurium, and to the dysregulation of a battery of genes required for the regulation of storage lipid metabolism in both the endoneurium and peri/epineurium. Together with the observation that these mutations also result in peripheral neuropathy, our findings demonstrate a crucial role for local storage lipid metabolism in mature peripheral nerve function, and have important implications for the understanding and treatment of peripheral neuropathies that are commonly associated with metabolic diseases such as lipodystrophy and diabetes.
\end{abstract}

[Keywords: Schwann cells; peripheral nerve development; fat metabolism; Charcot-Marie-Tooth disease; peripheral neuropathy; microarray analysis]

Supplemental material is available at http://www.genesdev.org.

Received May 27, 2003; revised version accepted August 4, 2003.

Among the most complex cellular interactions in vertebrate neural development is the interplay of neurons, glia, and mesenchymal cells that leads to the formation of peripheral nerves. A subset of these interactions occurs between neurons and Schwann cells, and results in the elaboration of myelin. This Schwann cell organelle consists of an extended sheet of specialized glial membrane that is repeatedly wrapped and then tightly compacted around axons (Webster 1971; Low 1976; Garbay et al. 2000). It provides the insulation upon which the rapid, saltatory conduction of neuronal action potentials is entirely dependent, and the loss of myelin integrity in demyelinating diseases is invariably debilitating (Keegan and Noseworthy 2002).

Peripheral nerves are composed of three distinct tissue compartments: the epineurium, perineurium, and endoneurium. The outermost epineurium surrounds a thin lamellated perineurium, which in turn surrounds the fascicle of axons, Schwann cells, and fibroblasts that make up the endoneurium. Schwann cells, the most abundant cells of the endoneurium, are derived from the

\footnotetext{
${ }^{1}$ These authors contributed equally to this work.

${ }^{2}$ Corresponding author.

E-MAIL lemke@salk.edu; FAX (858) 455-6138.

Article and publication are at http://www.genesdev.org/cgi/doi/10.1101/ gad.1116203.
}

neural crest via a multistep differentiation process involving the formation of a Schwann cell precursor that is present in mouse nerves beginning at embryonic day 12 to 13 (E12-E13), and subsequently, of an immature Schwann cell, present from E15 to birth (Jessen and Mirsky 1999). During the first postnatal week, a subset of immature Schwann cells exit the cell cycle, lose susceptibility to apoptosis, synthesize a basement membrane, and begin to myelinate their associated axons (Zorick and Lemke 1996). Myelination of peripheral nerves peaks in the second postnatal week in the mouse, after which the process substantially slows; only steady-state maintenance levels of myelin protein synthesis are observed in adult nerves (Garbay et al. 1998). In addition to adopting a myelinating phenotype, immature Schwann cells may alternatively differentiate into nonmyelinating Schwann cells, which loosely ensheath, without multilayered wrapping or compaction, multiple smallcaliber axons. These mature nonmyelinating Schwann cells first differentiate in the second postnatal week, and continue to express many of the genes characteristic of immature cells (Zorick and Lemke 1996).

The choice between a myelinating versus a nonmyelinating fate is highly significant with regard to Schwann cell metabolism and gene expression. Two Schwann cell transcription factors have been shown to play a pivotal role in myelinative differentiation: the 
POU protein Scip (Oct-6/Tst-1; Monuki et al. 1990; Bermingham et al. 1996; Jaegle et al. 1996; Zorick et al. 1996) and the zinc finger protein Krox-20 (Egr2; Swiatek and Gridley 1993; Topilko et al. 1994; Zorick et al. 1999).

In humans, the failure to assemble or properly maintain peripheral nervous system (PNS) myelin results in a heterogeneous group of disabling peripheral neuropathies. Most of these neuropathies are metabolic and acquired, notably as sequelae of diabetes. Diabetic peripheral neuropathy, whose molecular basis remains obscure, represents a substantial medical problem in humans, and accounts for the bulk of the $8 \%$ of the aged human population in which peripheral nerve damage is thought to occur (Martyn and Hughes 1997). In addition to these acquired conditions, a set of inherited peripheral neuropathies, collectively referred to as Charcot-MarieTooth disease (CMT) or hereditary motor and sensory neuropathy (HMSN), have also been described. Together, these familial disorders constitute a relatively common set of genetic diseases, with an estimated 1 in 2500 persons affected (Skre 1974).

The molecular mechanisms underlying many of the events of peripheral nerve development are poorly understood, and a systematic analysis of gene expression during these events has yet to be described. We therefore performed Affymetrix-based GeneChip analyses on mRNA populations isolated from sciatic nerves of the mouse, from late embryogenesis to adult. Unexpectedly, we identified a large cluster of genes that are most highly expressed only after myelination is complete. This cluster contains an abundance of genes related to storage lipid metabolism, many of which are expressed in the adipocytes that populate the epineurium of the mature peripheral nerve. Most interestingly, we found that several of these genes, including SREBP-1, SREBP-2, and Lpin1 are also expressed in the endoneurium. We demonstrate that null mutation of Lpin1, which results in a peripheral neuropathy, also leads to lipoatrophy of the epineurium and to dysregulation of storage lipid metabolism genes and their products in the mature nerve.

\section{Results}

Developmental expression profiling of mouse sciatic nerve

Microarray analyses were performed with mRNA samples isolated from mouse sciatic nerves dissected at E17 and at postnatal days 0, 2, 4, 10, and 56 (P0-P56; Fig. 1). Schwann cells account for the clear majority of the cells present in the sciatic nerve during the first 3 postnatal weeks (Low 1976; Brockes et al. 1979; Nakao et al. 1997), and the levels of neuronal mRNAs present in the sensory and motor axons of the nerve are thought to be very low (Mohr 1999). The time points selected therefore allow for the sampling of Schwann cell mRNA populations from premyelinating (E17), promyelinating (P0, $\mathrm{P} 2$ ), and myelinating nerves (P4, P10). (For raw array data, see Supplementary Table S1.)

The differentiation of Schwann cells in the sciatic

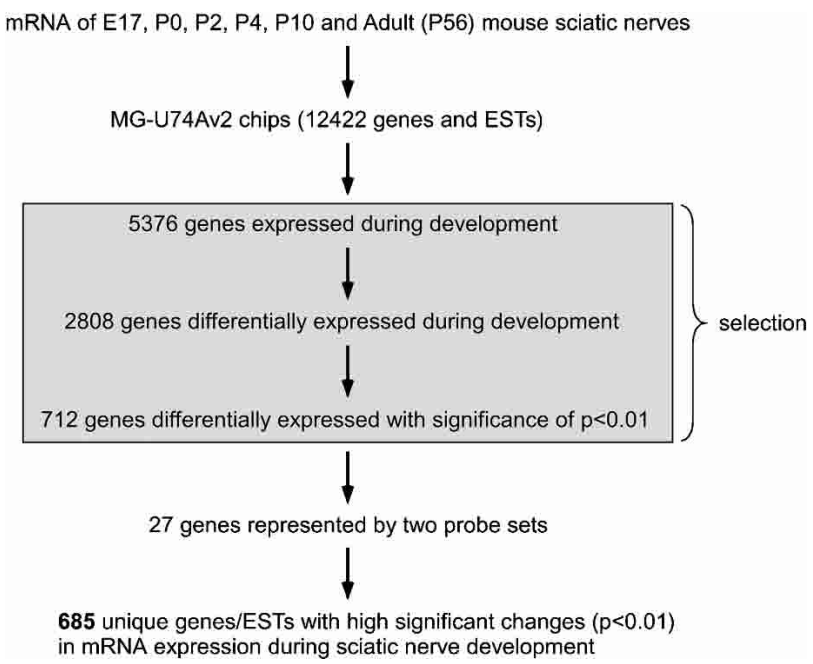

Figure 1. Scheme of GeneChip analysis of mouse sciatic nerve development. For a detailed description of software-based selection, see Materials and Methods.

nerve progresses in a proximal-to-distal wave (where proximal is close to the spinal cord), such that Schwann cells in a distal segment of the nerve are at approximately the same developmental stage as more proximal cells were 1-2 d earlier (Zorick et al. 1996). Because we dissected a relatively large segment of the nerve, from distal of the sciatic notch to proximal of the knee, we selected for the analysis those mRNA hits that were scored as "present" (see Materials and Methods) in duplicate samples from at least two consecutive time points between E17 and P56. The E17 and P56 samples lack a consecutive time point, and we therefore included those mRNAs scored as "present" in duplicate samples of these single time points. This filter yielded an initial group of 5376 mRNAs expressed in the nerve from E17 to P56 (Fig. 1). Of this group of 5376 genes, 2808 were found to systematically vary (increase or decrease) in expression level as a function of developmental time, and were classified as differentially expressed during sciatic nerve development (Fig. 1). For 712 genes of this group, expression across the different time points showed significant differences with a P-value cutoff of 0.01 in ANOVA. Analysis using the NCBI Blast, Unigene, and SOURCE databases revealed that 27 of the 712 genes were represented by two probe sets. Of these 27 duplicated sets, 26 yielded essentially identical expression data for both probe sets (see Supplementary Fig. S2). This correspondence is indicative of a reproducible and semiquantitative assay. Thus, 685 unique genes/ESTs were selected as displaying the most significant expression changes during sciatic nerve development (Fig. 1).

\section{Systematic identification of peripheral neuropathy candidate genes}

For about half of the 35 described forms of hereditary peripheral neuropathy, the causal genes remain to be 
identified, although they have been mapped to more or less well-delimited regions in the genome (Bennett and Chance 2001). To facilitate the identification of these genes, and of those mapped in the future, we used our GeneChip data to establish biological selection criteria. For all of the 685 genes exhibiting the most pronounced developmental regulation, we determined the human homolog and its chromosomal location, whenever available, using the public databases SOURCE and Locuslink (Supplementary Table S3A). We thereby identified 22 candidate genes for nine distinct CMT loci (Table 1, Supplementary Table S3B). For example, the intermediate disease I-CMT2 has been mapped to a locus containing 133 genes (10q24.1-q25.1, D10S1709-D10S1795), of which three were selected by our screen. The fact that these three genes exhibit significant changes in expression during peripheral nerve development makes them attractive candidate genes for this disease.

To establish proof-of-principle for this approach, we performed a post hoc retrospective analysis of our list of candidate genes (Table 2). We asked whether previously cloned peripheral neuropathy disease genes, such as those encoding PMP22, CX32, EGR2, and MPZ (Bennett and Chance 2001) would have been selected as candidate genes by our screen. We found that the majority of genes whose mutant alleles have previously been tied to demyelinating forms of CMT were indeed identified by the screen, with the exception of PRX and LITAF (which were detected as being expressed, but not differentially so, throughout peripheral nerve development) and $M T M R 13$ [which was detected as being differentially expressed, but did not make the significance threshold $(p<0.01)$ for selection]. Ganglioside-induced differentiation-associated protein-1 (GDAP1), which causes both axonal and demyelinating forms of CMT4A (Baxter et al.
2002; Cuesta et al. 2002), could not be detected. This is in agreement with published observations that GDAP1 mRNA expression is high in dorsal root ganglia but very low in sciatic nerve (Cuesta et al. 2002). In addition, we have observed that the gene encoding glycyl tRNA synthetase $(G A R S)$, previously described as being mutated in an axonal form of CMT2D, was also identified by our screen. This, together with previous observations that mutations in a gene expressed in Schwann cells (MPZ) can lead to both demyelinating and axonal phenotypes (Vance 2000), extends the validity of our candidates to both demyelinating and axonal forms of CMT.

\section{Primary expression profiles during peripheral nerve development}

To identify distinct temporal expression profiles and thereby segregate the 685 highly differentially expressed genes, K-means clustering was performed. This yielded five clusters (Fig. 2A), which we validated with a set of marker genes whose expression levels during the course of Schwann cell differentiation have already been well described. We also independently validated the GeneChip data for each of these marker genes with quantitative polymerase chain reaction (Q-PCR; Fig. 2B).

Cluster 1 consisted of 247 genes that were highly expressed at E17, and then down-regulated during the course of subsequent peripheral nerve development. Several genes with this expression profile have been described, among which is Ncam, a marker for nonmyelinating and immature promyelinating Schwann cells that is markedly down-regulated upon differentiation into myelinating cells (Jessen et al. 1987). Ncam was present on our Affymetrix GeneChips, was indeed included in

Table 1. Candidate disease genes for different types of peripheral neuropathy

\begin{tabular}{|c|c|c|c|c|c|}
\hline Type & OMIM\# & Form & Locus $^{\mathrm{a}}$ & Total genes in locus ${ }^{\mathrm{b}}$ & Selected genes in locus ${ }^{c}$ \\
\hline I-CMT2 & 606483 & Intermediate & $\begin{array}{c}\text { 10q24.1-q25.1 } \\
\text { D10S1709-D10S1795 }\end{array}$ & 133 & 3 \\
\hline I-CMT1 & 606482 & Intermediate & $\begin{array}{c}\text { 19p12-p13.2 } \\
\text { D19S586-D19S432 }\end{array}$ & 208 & 2 \\
\hline dHMN VII & 158580 & Axonal & $\begin{array}{c}2 \mathrm{q} 14 \\
\mathrm{D} 2 \mathrm{~S} 2264-\mathrm{D} 2 \mathrm{~S} 2215\end{array}$ & 302 & 3 \\
\hline CMT2F & 606595 & Axonal & $\begin{array}{c}\text { 7q11 } \\
\text { D7S2435-D7S806 }\end{array}$ & 121 & 2 \\
\hline dHMN-J & 605726 & Axonal & $\begin{array}{c}\text { 9p21.1-p12 } \\
\text { D9S1845-D9S1791 }\end{array}$ & 91 & 1 \\
\hline HMN II & 158590 & Axonal & $\begin{array}{c}12 \mathrm{q} 24 \\
\mathrm{D} 12 \mathrm{~S} 86-\mathrm{D} 12 \mathrm{~S} 340\end{array}$ & 124 & 1 \\
\hline SMAL & 600175 & Axonal & $\begin{array}{c}\text { 12q24 } \\
\text { D12S78-D12S1646 }\end{array}$ & 143 & 4 \\
\hline HNA & 162100 & Axonal & $\begin{array}{c}17 q 25 \\
\text { D17S722-D17S802 }\end{array}$ & 24 & 2 \\
\hline AR-CMT2B-2 & 605589 & Axonal & $\begin{array}{c}\text { 19q13.3 } \\
\text { D19S606-D19S585 }\end{array}$ & 134 & 4 \\
\hline
\end{tabular}


Table 2. Retrospective analysis of cloned peripheral neuropathy disease genes

\begin{tabular}{|c|c|c|c|c|c|c|c|}
\hline Type & OMIM\# & Form & Locus $^{\mathrm{a}}$ & $\begin{array}{l}\text { Total genes } \\
\text { in locus }{ }^{\mathrm{b}}\end{array}$ & $\begin{array}{l}\text { Selected genes } \\
\text { in locus }{ }^{\mathrm{c}}\end{array}$ & $\begin{array}{l}\text { Mutated } \\
\text { gene }\end{array}$ & $\begin{array}{l}\text { Mutated gene } \\
\text { in selection }^{\mathrm{d}}\end{array}$ \\
\hline CMT1A & 118220 & Demyelinating & $17 \mathrm{p} 11.2-11.1$ & 192 & 2 & PMP22 & Yes \\
\hline СMT1B & 118200 & Demyelinating & $1 q 22-q 23$ & 209 & 8 & $M P Z$ & Yes \\
\hline CMT1C & 601098 & Demyelinating & $16 \mathrm{p} 13.1-\mathrm{p} 12.3$ & 81 & 1 & LITAF & No \\
\hline CMTX & 302800 & Demyelinating & $\mathrm{Xq} 11.2-\mathrm{Xq} 21.1$ & 187 & 2 & CX32 & Yes \\
\hline CMT4D-Lom & 601455 & Demyelinating & $8 \mathrm{q} 24$ & 43 & 2 & $N D R G 1$ & Yes \\
\hline CMT4E & 605253 & Demyelinating & No linkage data (10q22) & & & $E G R 2$ & Yes \\
\hline СMT3 & 145900 & Demyelinating & $19 \mathrm{q} 13.1-13.3$ & 291 & 8 & $P R X$ & No \\
\hline CMT4B2 & 604563 & Demyelinating & $11 \mathrm{p} 15$ & 67 & 2 & MTMR13 & $\mathrm{No}^{\mathrm{e}}$ \\
\hline CMT4A & 214400 & Demyelinating/axonal & $8 q 13-21$ & 212 & 4 & $G D A P 1$ & No \\
\hline СMT2A & 118210 & Axonal & $1 \mathrm{p} 35-\mathrm{p} 36$ & 62 & 2 & $K 1 F 1 B$ & No \\
\hline СМТ2B & 600882 & Axonal & $3 q 13-q 22$ & 135 & 4 & $R A B 7$ & No \\
\hline CMT2D & 601472 & Axonal & $7 \mathrm{p} 15$ & 22 & 3 & GARS & Yes \\
\hline AR-CMT2-1 & 605588 & Axonal & $1 \mathrm{q} 21.2-\mathrm{q} 21.3$ & 159 & 3 & $L M N A$ & No \\
\hline HSN1 & 162400 & Axonal & $9 q 22$ & 30 & 3 & SPTLC1 & No \\
\hline SMA1 & 253300 & Axonal & $5 q 12-q 13$ & 176 & 1 & SMN1 & $\mathrm{No}^{\mathrm{e}}$ \\
\hline
\end{tabular}

${ }^{a}$ Locus of peripheral neuropathy as described prior to identification of disease gene.

b,c See Table 1 for definitions.

${ }^{\mathrm{d}}$ Defines if mutated gene is among selected genes $(p<0.01)$ in locus.

${ }^{\text {e}}$ Detected as being differentially expressed (but not reaching $p<0.01$ significance).

cluster 1 by our clustering paradigm, and served as a validating marker for this cluster (Fig. 2B).

Cluster 2 contained a small group of 42 genes exhibiting down-regulation after E17 and then modest upregulation in adult (P56) sciatic nerves. This "U-like" pattern has not been previously described for peripheral nerve. Comparison of GeneChip data and Q-PCR for this cluster was carried out with lactate dehydrogenase $(L d h$; Fig. 2B), an enzyme demonstrated to be highly expressed in cultured Schwann cells (Rust et al. 1991).

Cluster 3 consisted of 49 genes up-regulated early in postnatal development, with an expression maximum at P0-P2, and then down-regulated as peripheral nerve development proceeds (P10 and P56). This expression pattern, with a transient peak corresponding to the presence of promyelinating Schwann cells, has also been previously documented, notably for the transcription factor Scip (Zorick et al. 1996). As predicted, Scip was included in cluster 3 , and served as a reliable validating marker for this set of "transitional" genes (Fig. 2B).

The 61 genes in cluster 4 exhibited an expression profile similar to those of cluster 3 , but with peak expression later in development (around P10), and an extended period of elevation. Cluster 4 contained all of the well known markers for myelinating Schwann cells that were present on our chips, for example, Krox-20 and the myelin structural protein genes $M p z, P m p 22$, and Mbp. Plp, a gene required for both PNS and CNS myelination (Garbern et al. 1997), served as a validation marker for this major cluster (Fig. 2B).

Prior to undertaking our analysis, we anticipated that cluster 4 would represent the last significant cluster of genes to be identified in the course of sciatic nerve development, because Schwann cells account for the majority of the cells present in the sciatic nerve (Low 1976; Brockes et al. 1979; Nakao et al. 1997) and have been thought to exist in the mature nerve in a relatively quiescent "maintenance" state (Peters et al. 1991). We were therefore surprised to identify a large cluster of 286 genes (the largest cluster) that were expressed at low levels in perinatal sciatic nerve and were up-regulated only in adult (P56) mouse nerves, after the bulk of peripheral myelination is complete. This expression profile is remarkable but not unprecedented, in that it has been described for at least one gene-Itgb4 ( $\beta 4$-integrin; Einheber et al. 1993; Feltri et al. 1994). Again, this gene was binned into cluster 5 by our clustering paradigm, and served as a validating marker for this set of late-onset genes (Fig. 2B). Comparison of GeneChip with Q-PCR data for the validating markers of each of the clusters revealed strong agreement, both in qualitative expression profiles, and in most cases, in quantitative (absolute) measurements. This validates our clustering parameters, and supports the reproducibility and semiquantitative aspects of the GeneChip assay.

\section{Expression profiles and biological functions}

We next organized the genes of clusters $1-5$ as a function of known or hypothesized biological activity (see Supplementary Table S4). Broad annotations (nodes) revealed characteristic spectra of biological functions for each of the five clusters (Fig. 3), and detailed annotations (subnodes) were used to plot the expression profiles for more than 100 gene groups with similar biological functions (see Supplementary Fig. S5).

Cluster 1 was notable for the prominence of genes involved in the regulation of the cell cycle, in nucleic acid metabolism, and in apoptosis (Fig. 3). Among the latter were Acinus, Apaf1, Pdd5, and Peg3, which are known positive mediators of apoptosis. The maximal expression of these pro-apoptotic genes in dividing premyelinating 
Verheijen et al.
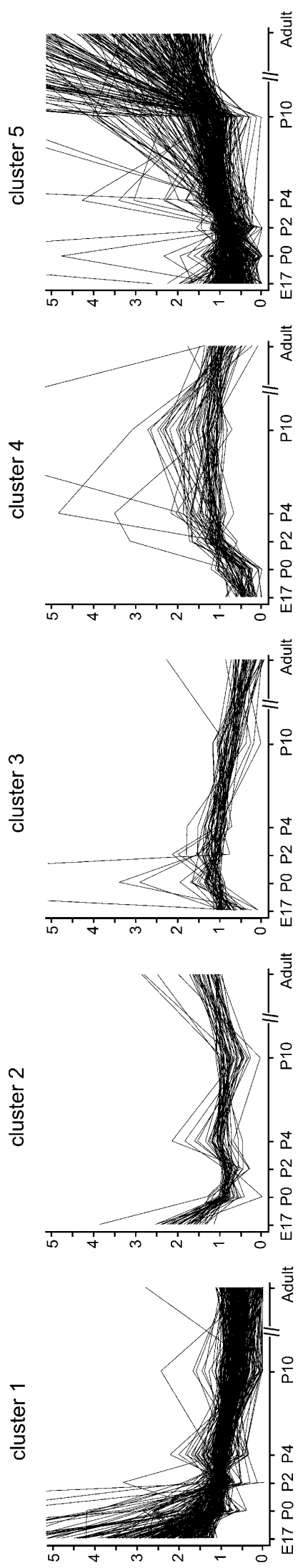

$\varangle \quad$ uo!ssajdxə $\forall$ Nyum pəz!||emson

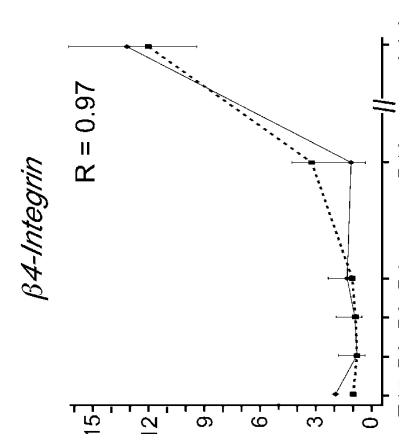

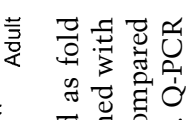

음

\& $\pi$ चี

s t

5 5 용

న

员

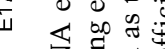

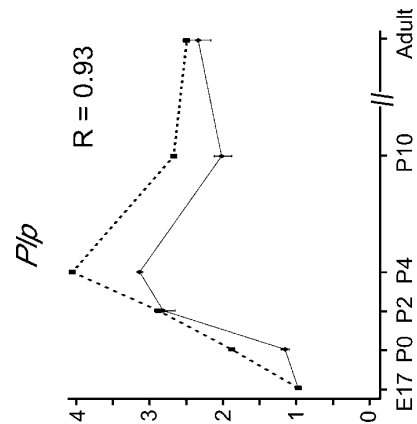

$\exists$ 记

๕ घ द्वे

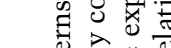

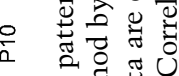

苛苞造过

象

文 $x^{2}$

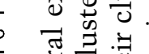

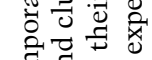
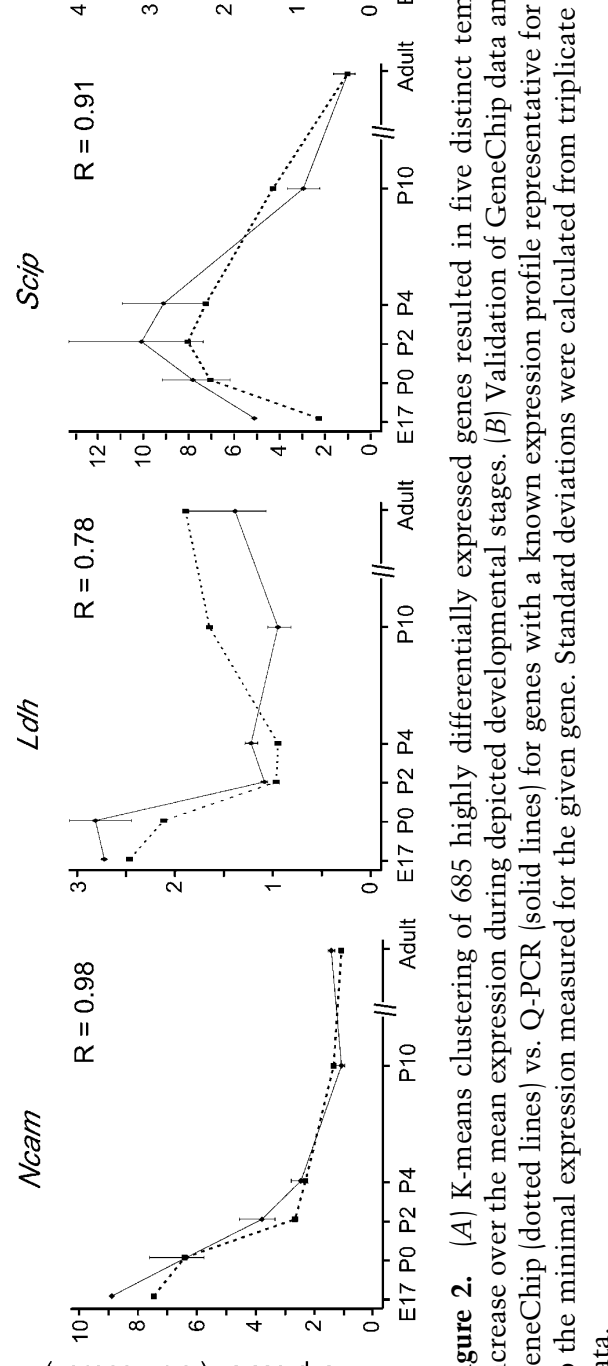

m (uo!nonpu! plof) uolssardxa $\forall N$ YYm 

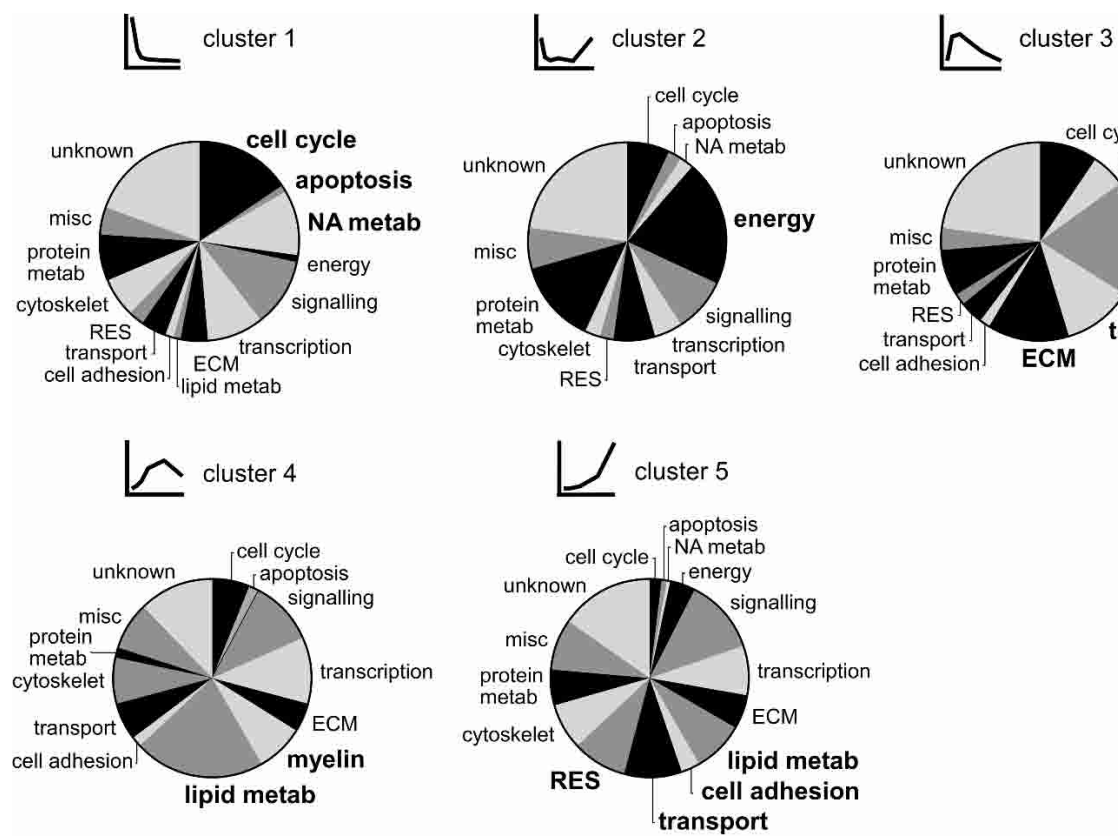

Figure 3. Association of clusters with biological function. The number of genes per class is depicted as a fraction of the total genes for each cluster. Significant classes for particular clusters are highlighted. For methods of annotation, see Materials and Methods.

cells contrasts with the presence of anti-apoptotic genes in later clusters associated with myelination (Mapk8ip in cluster 4 and Bcl212, Serpinf1, and Tax1bp1 in cluster 5). Cluster 1 also included 46 genes associated with the positive regulation of the cell cycle, including key regulators such as Cdk4 and $C d c 2$, and cyclin D1, cyclin D2, cyclin $A 2$, cyclin $B 1$, and cyclin B2, and 13 genes involved in DNA metabolism, for example, the histones H2afX, H2afy, and H2bfs, and Top2 (DNA topoisomerase II). The maximal expression of these proliferation genes in premyelinating cells was in contrast to the presence of cell-cycle arrest genes in later stages of development (including Pcbp4 in cluster 3, p21Cip1 in cluster 4, and Ndrg1 in cluster 5). Also prominent in cluster 1 were genes involved in RNA metabolism, protein synthesis, protein folding, and nucleocytoplasmic transport.

An interesting feature of cluster 2 was the relatively high number of genes (9 out of 42) involved in energy pathways, including glucose metabolism as well as cytochrome and NADH dehydrogenase subunits. These were expressed in premyelinating nerves, down-regulated during early postnatal development, and subsequently up-regulated in adults.

Cluster 3 genes are characterized by an expression profile that peaks in the first few days immediately after birth. In addition to the transcription factor Scip (see above), this cluster contained a large number of other transcription factors, such as Sox4, Nab2, and Id2.

As expected, cluster 4-mRNAs whose expression was maximal at P10 - contained all of the structural genes associated with the deposition and compaction of the myelin sheath, for example, $M b p, P m p 22$, and $M p z$. In addition, this cluster contained a large number of genes (12) involved in the synthesis, transport, and metabolism of structural lipids. The latter observation is consistent with the fact that myelinating cells must synthesize and extend an extraordinary volume of specialized membrane per day (Webster 1971).

As noted above, both the existence of a cluster 5 (mRNAs highly expressed only in adult nerves) and its large size (286 genes) were unexpected findings. Included in this cluster were genes involved in cell adhesion, ion transport, and responses to external stimuli (RES), which includes antigen presentation and complement activation. In addition, this cluster exhibited a provocative composition with regard to lipid metabolism.

\section{Differential regulation of lipid metabolism}

Nearly all genes annotated as relevant to "lipid metabolism" were maximally expressed at either P10 (myelination cluster 4) or P56 (mature nerve cluster 5). More detailed annotation, however, revealed that the segregation into either cluster 4 or cluster 5 was tightly correlated with the extent to which individual genes were tied to the production of structural (myelin membrane) lipids versus the metabolism of storage (energy) lipids (Fig. 4A).

Included in the genes of cluster 4, for example, are 10 genes involved in the biosynthesis of cholesterol and galactocerebroside, two major components of the myelin membrane (see Supplementary Fig. S5). Among the 15 genes encoding cholesterol biosynthetic enzymes that were present on the chip, 12 followed the cluster 4 expression profile, and the remaining three genes did not display significant changes in expression during development (Fig. 4B,C). Similar expression was observed for seven genes involved in biosynthesis or metabolism of plasma membrane glyco- and phospholipids (Fig. 4B). 
Verheijen et al.

A

C

\section{Cholesterol biosynthesis}

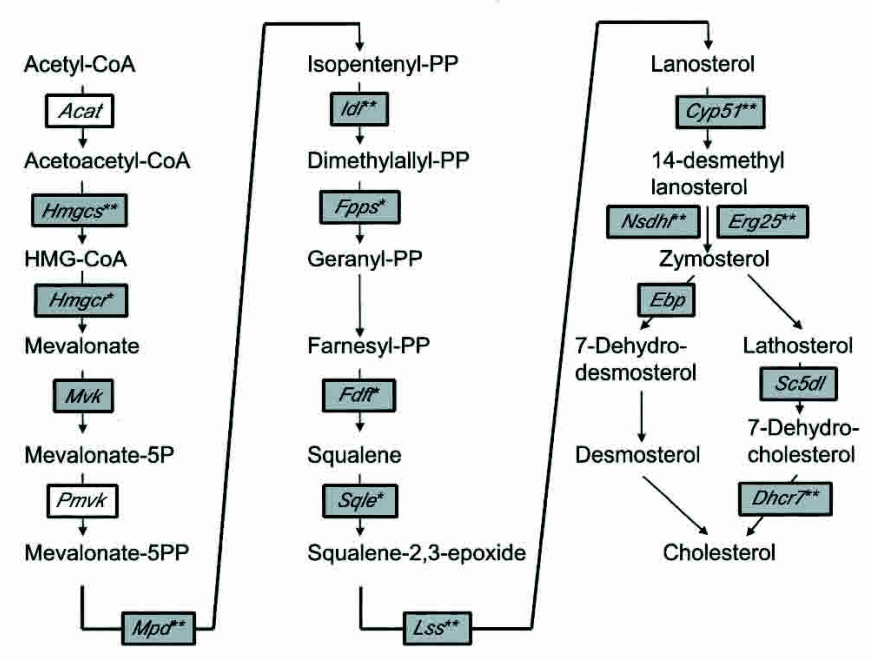

B

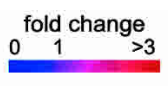

Cholesterol biosynthesis

biosynthesis of myelin membrane lipids

metabolism of storage
lipids

Membrane lipid biosynthesis
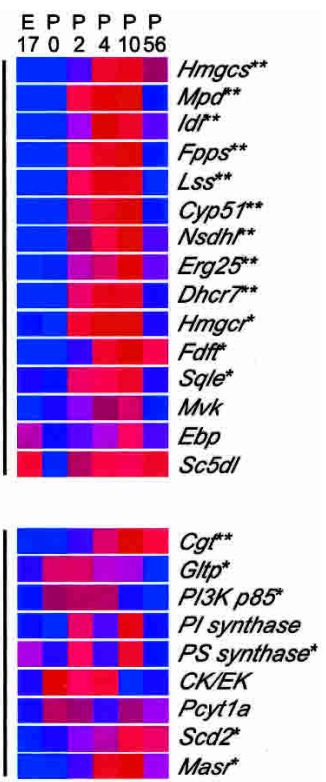

D

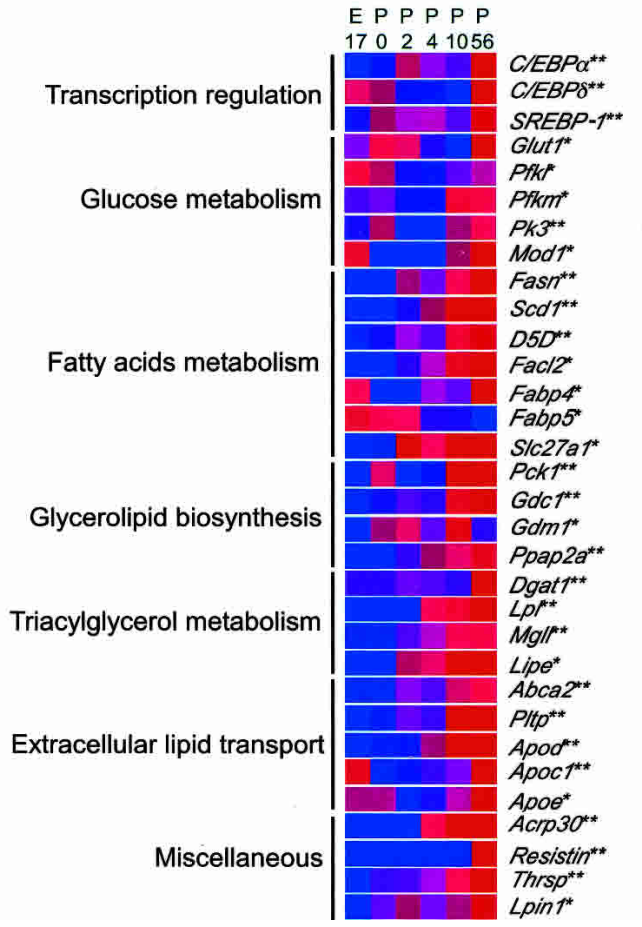

Figure 4. Different temporal expression of genes involved in myelin membrane lipid biosynthesis and storage lipid metabolism. $(A)$ Expression profile of highly differentially expressed genes regulating the metabolism of myelin membrane lipids (green) and storage lipids (black). mRNA expression is presented as fold increase over the mean expression during depicted developmental stages. $(B)$ Expression profile of selected genes involved in biosynthesis of cholesterol and membrane lipids. All genes are expressed at some point during myelination, with the differentially expressed genes marked as ${ }^{*}$, and the highly differentially expressed genes $(p<0.01)$ marked as ${ }^{\star \star}$. (C) Scheme of the cholesterol biosynthesis pathway in which the site of action is shown for the genes presented in $B$. Genes in white boxes were not present on the chip. $(D)$ Expression profile during peripheral nerve development of selected genes known to be involved in distinct aspects of storage lipid metabolism in adipocytes and hepatocytes.

Most interestingly, two genes involved in the biosynthesis of oleate, Scd2 and Masr (also called Lce), appeared in cluster 4 rather than cluster 5 , and unusually, this specific fatty acid serves primarily as a structural compo- nent of PNS myelin rather than as an energy source (Garbay et al. 1998; Nagarajan et al. 2002).

In marked contrast, the "lipid metabolism" genes of cluster 5 encoded proteins involved in the metabolism of 
fatty acids and storage lipids, and in the catabolism of phospholipids. Given this unexpected result, we further searched for differentially expressed genes known to be involved in storage lipid metabolism in other cells, most notably adipocytes and hepatocytes (Fig. 4D). Nearly all such genes that we assayed are also strongly up-regulated in adult nerves. The adult-onset genes we detected are involved in multiple aspects of fatty acid and triacylglycerol (TAG) metabolism. In addition, several transcription factors known to regulate the expression of lipid metabolism genes in adipocytes and hepatocytes, including $C / E B P \alpha, C / E B P \delta$, and $S R E B P-1$, also showed strong up-regulation in adult nerves. A similar adult-onset expression profile was found for two secreted factors of adipocytes, Acrp30 and Resistin, as well as for lipid transport genes, such as Apoc1, Apod, Apoe, Pltp, Lpl, and $A b c a 2$, which are all involved in extracellular lipid transport and all appeared in cluster 5. Q-PCR assays were performed for Scd1, SREBP-1, Lpl, and Acrp30, which confirmed their peak expression in adult sciatic nerves (data not shown). Thus, genes tied to the structural lipids of myelin (e.g., cholesterol, phospholipids, and galactolipids) or to storage lipids (e.g., fatty acids and TAGs) segregated alternatively into cluster 4 and cluster 5 , respectively.

Although Schwann cells account for the vast majority of cells in the peripheral nerve (Low 1976; Brockes et al. 1979; Nakao et al. 1997), it is important to establish whether genes binned into each of the above clusters are or are not expressed by these cells. First, hematoxylin and eosin stainings were performed on dissected sciatic nerves to determine differences in cellular composition of P10 versus adult sciatic nerves (Fig. 5). An unanticipated large amount of adipose-like tissue was observed in the epineurial compartment of adult sciatic nerves, in marked contrast to P10 nerves. Interestingly, the amount of adipose-like tissue in the adult nerve increased from proximal to distal, where proximal is close to the spinal cord and distal is close to the knee joint (Fig. 5).

In situ hybridization on the distal region of the adult sciatic nerve was used to determine the site of expres- sion of many of the storage lipid metabolism genes in the peripheral nerve. Figure 6 shows that expression patterns for this group of genes can be roughly divided into three classes. One class consisted of genes only expressed in the epineurium; these included Acrp30, Resistin, and Lpl, consistent with the observed preponderance of adipocytes in this sheath. A second class contained genes expressed in both the endoneurium and peri/epineurium, such as SREBP-1, SREBP-2, Scd1, Apoe, and Fasn. Itgb4 ( $\beta 4$-integrin) was previously shown to be expressed in both the endoneurium and peri/epineurium (Feltri et al. 1994), and was therefore used as a control. A third class (two genes) showed expression only in the endoneurium: Scd2 and Apod. Importantly, for all of the endoneurial mRNAs in Figure 6, comparison with the mRNA localization of myelin $\mathrm{P}_{0}(\mathrm{Mpz})$ strongly suggests that Schwann cells are the main site of their expression. Indeed, immunostaining staining of SREBP-1 in the adult sciatic nerve demonstrated that SREBP-1 protein is expressed by myelinating Schwann cells in the endoneurium as well as by adipocytes in the epineurium, where it is localized both within and close to the nuclei of both cell types (Fig. 7).

For selected genes, the contribution in mRNA expression made by the endoneurium versus the peri/epineurium of the adult sciatic nerve was also determined by Q-PCR, after physical separation of these compartments (Fig. 8A). That this separation was successful is demonstrated by the fact that the peri/epineurial fraction contains almost no Schwann cell-specific mRNAs (e.g., $M p z, P l p$, and Krox-20), whereas the endoneurial fraction contains almost no adipocyte-specific mRNAs (e.g., $L p l$ and Acrp30). These data show that for genes expressed only in the peri/epineurium compartments (Thrsp, $C / E B P \alpha$, Resistin, Lpl, and Acrp30), the observed increase in mRNA expression in adults (cluster 5) is entirely due to the appearance of adipocytes in the mature epineurium. For cluster 5 genes that are expressed in both the endoneurium and the peri/epineurium (Apoe, ß4-integrin, C/EBP, SREBP-1, Fasn, Lpin1, and Scd1), the onset of expression in adults is mainly, although not entirely, derived from the appearance of adipocytes in

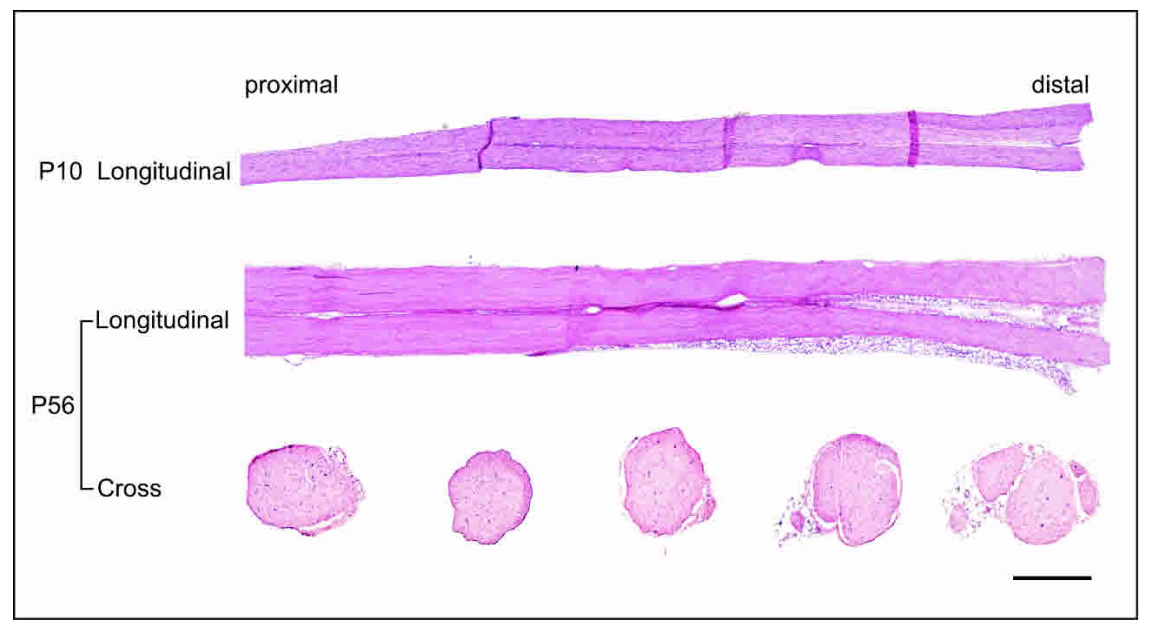

Figure 5. Hematoxylin and eosin staining of P10 (longitudinal section) and adult (P56) sciatic nerve (both cross- and longitudinal sections). Adipocytes are abundant in distal regions of the adult nerve. The sciatic nerves shown are representative for at least five nerves studied per stage. Bar, $300 \mu \mathrm{m}$. 
Verheijen et al.

Figure 6. ${ }^{33} \mathrm{P}$-RNA in situ hybridization signal on adult (P56) mouse sciatic nerve for depicted genes illustrates their expression in endoneurium only $(M p z, S c d 2$, and Apod), in both endoneurium and peri/epineurium (SREBP-2, Scd1, Apoe, SREBP-1, Fasn, and $\beta 4$-integrin), or only in peri/epineurium (Acrp30, Resistin, and Lpl). Results shown are representative for at least a duplicate experiment. Bar, $50 \mu \mathrm{m}$.
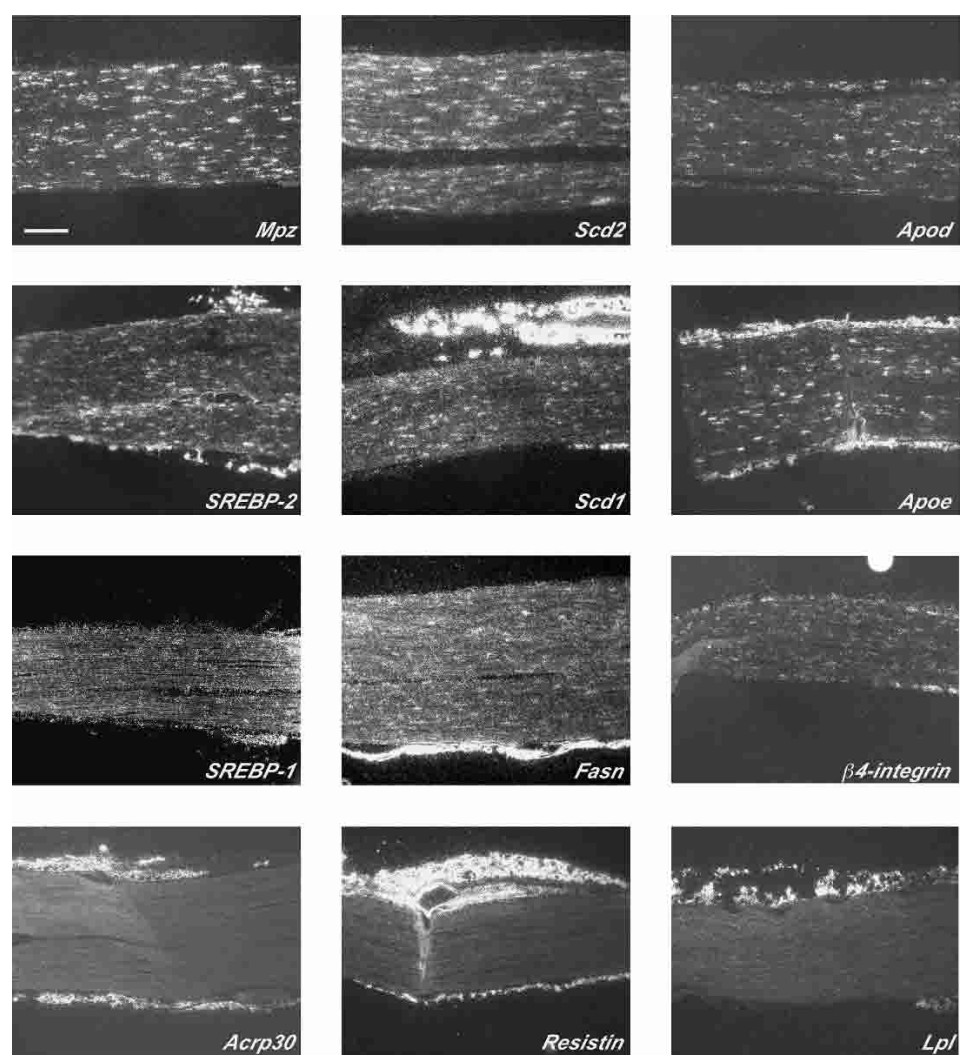

adult nerves. Apod is the only gene we analyzed for which the increase in adults is mainly derived from expression in the endoneurium. Figure $8 \mathrm{~B}$ shows that for genes specific to the endoneurium $(M p z)$, peri/epineurium (Thrsp and Acrp30), or both compartments (Fasn and $A$ poe), the expression of protein correlates very well with mRNA expression.

Lpin 1 is expressed in the peripheral nerve and is required for its function

Lipin1 is the product of the Lpin1 gene, which is mutated in fatty liver dystrophy (fld) mice (Peterfy et al. 2001). These mice are characterized by a neonatal fatty liver that resolves at weaning, lipoatrophy, and a progressive demyelinating neuropathy affecting peripheral nerves (Langner et al. 1989, 1991; Reue et al. 2000). Observations on the sciatic nerve in these mice show a variety of abnormalities, including poorly compacted myelin sheaths, active myelin breakdown, and hypertrophic Schwann cells (Langner et al. 1991). We have found that the lipodystrophy in adult Lpin 1 mutants extends to the epineurium of the sciatic nerve. Staining of storage lipids in the epineurium with Oil Red O highlights the presence of large fat deposits in the epineurium of wildtype sciatic nerves, and these fat deposits are severely reduced in the Lpin1 mutants (Fig. 9A). Detailed observations on the mid-region of the nerve revealed that

Figure 7. (A) Immunolabeling of SREBP-1 (red) and neurofilament (green) or DAPI staining (blue) shows that SREBP-1 protein is expressed in both Schwann cells and adipocytes (Ad) of adult mouse sciatic nerve. $(B)$ SREBP-1 is expressed in and close to nuclei $(\mathrm{N})$ of myelinating Schwann cells (SC) surrounding an axon (Ax). Result shown is representative of at least three immunostainings. Bars, $10 \mu \mathrm{m}$.
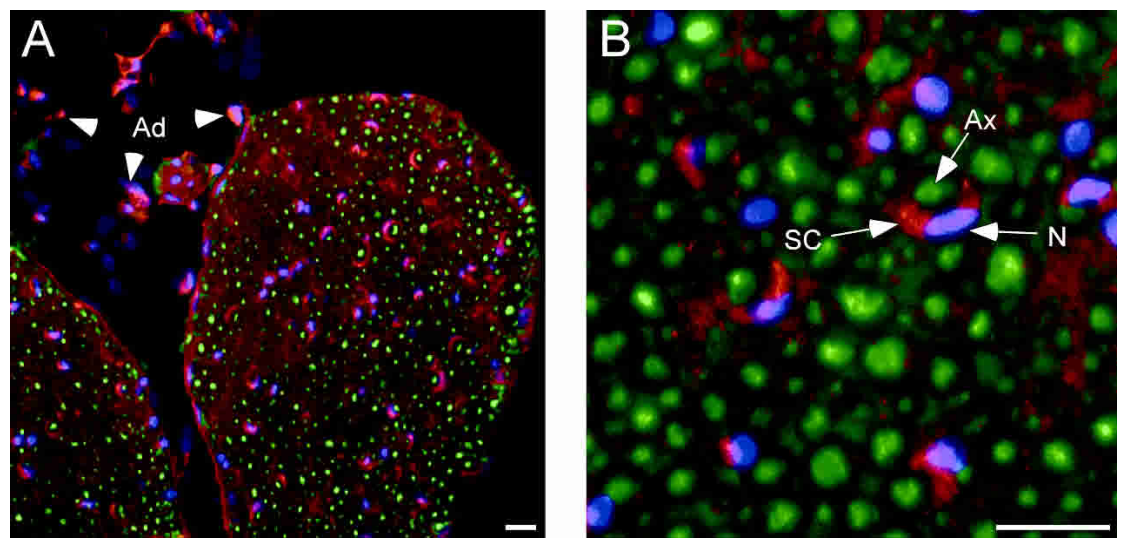
A

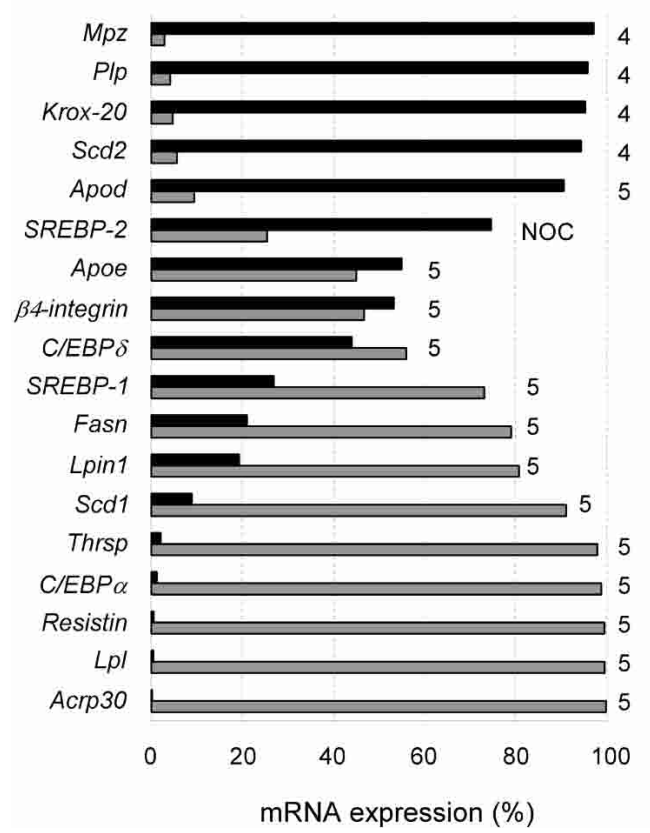

B

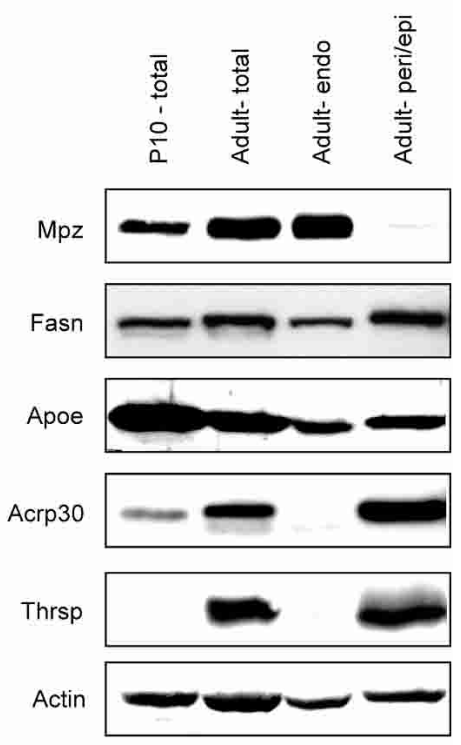

Figure 8. Quantitation of expression of lipid metabolism genes in different compartments of the adult sciatic nerve. $(A)$ QPCR on endoneurium and peri/epineurium fractions of adult sciatic nerve (P56) for depicted genes. Numbers next to bars depict the cluster associated with that mRNA. (NOC) Not on chip. Data are averages of triplicate experiments. $(B)$ Western blots on total lysates (40 $\mu \mathrm{g}$ ) of P10 and adult (P56), or endoneurium $(24 \mu \mathrm{g})$ or peri/epineurium $(16 \mu \mathrm{g})$ fractions of adult sciatic nerve, for depicted proteins. Note that the protein amount of adult endoneurium and peri/epineurium fractions loaded are relative to their contribution to the protein amount of total adult nerve. Protein samples were derived from at least eight sciatic nerves.

lipid-filled adipocytes are uniformly shaped and linearly arranged in wild-type mice, mainly between branches of nerves. In marked contrast, in the Lpin1 mutants lipidfilled adipocytes are strongly reduced in number and irregularly shaped (Fig. 9B). Cell counts of lipid-filled adipocytes in the mid-region of the nerve revealed a reduction of $\sim 70 \%$, which is comparable to the reduction in adipose mass in Lpin1 mutant mice documented for adult inguinal and epididymal fat pads (Reue et al. 2000).

Lpin1 mRNA has been reported to be undetectable in the mouse sciatic nerve at P21 (Peterfy et al. 2001), leading to the conclusion that the neuropathy in Lpin1 mutant mice is a secondary effect of Lipin1 deficiency in other tissues. However, our GeneChip and Q-PCR data demonstrate that Lpin1 mRNA is indeed expressed in the adult (P56) sciatic nerve (Figs. 4D, 8A). We therefore examined the expression of this mRNA during sciatic nerve development using Q-PCR, and included a P28 time point in our analysis. Lpin1 mRNA is unambiguously expressed during the first $4 \mathrm{wk}$ of peripheral nerve development, albeit at low levels (Fig. 9C). In agreement with our GeneChip data, we find that this expression is strongly up-regulated thereafter, such that Lpin1 segregates as a "cluster 5" gene; its late-onset profile is due largely to expression in the peri/epineurium. Finally, Western blotting confirmed expression of Lipin1 protein (MW $\sim 140 \mathrm{kD}$ ) in both the endoneurium and the peri/ epineurium fractions of wild-type but not mutant adult sciatic nerves (Fig. 9D).

Interestingly, the epineurium of Lpin1 mutants displays reduced Fasn protein levels. This is in agreement with our observations that mutant epineurium has reduced storage lipid content. Importantly, the endoneurium of Lpin1 mutants also displays lower Fasn protein levels, as well as reduced Mpz levels, whereas Apoe levels are strongly increased (Fig. 9D). Together, these observations suggest that the neuropathy and lipoatrophy of the peripheral nerve are direct consequences of the absence of Lipin $1-$ and the attendant dysregulation of storage lipid metabolism-within the nerve itself.

\section{Discussion}

\section{Regulation of gene expression during peripheral nerve myelination}

Earlier studies have indicated that premyelinating Schwann cells exit the cell cycle and lose susceptibility to apoptosis at the onset of myelination (Stewart et al. 1993; Syroid et al. 1996; Nakao et al. 1997; Zorick et al. 1999|. Our expression data reinforce this view, because genes associated with proliferation and apoptosis are highly expressed in late embryonic nerves and are downregulated during subsequent development, in contrast to cell-cycle arrest and anti-apoptotic genes, which are upregulated during myelinative differentiation. Our data further demonstrate that the transition to myelination is associated with decreased expression of genes involved in RNA metabolism, protein biosynthesis, protein folding, nucleocytoplasmic transport, and energy metabolism.

The onset of active myelination is associated with the up-regulation of a large battery of genes required for the synthesis of the myelin membrane (cluster 4). Our observation of strict coexpression of myelin protein genes with genes involved in the biosynthesis of cholesterol and galactolipids in developing Schwann cells, together with similar observations recently reported for transected and crushed nerves (Nagarajan et al. 2002), are of particular interest given the demonstration that myelin 
Verheijen et al.

Figure 9. Lpin1 is expressed in the sciatic nerve where it is required for storage lipid metabolism. (A) Staining of storage lipids with Oil Red $\mathrm{O}$ in adult wild-type and Lpin1 mutant (fld/fld) sciatic nerve. Note the strong reduction in size of fat deposits (dark red; arrowheads) in the Lpin1 mutant nerve. Data are representative of at least three animals studied per genotype. $(B)$ Higher magnification of the central section of the nerves presented in $A$. Arrowheads point to fat-filled adipocytes. Note the lines of uniformly sized adipocytes in the wild-type nerve, in contrast to the few irregularly shaped adipocytes in the Lpin1 mutant. (C) Q-PCR measurements on Lpin1 mRNA at depicted developmental stages of total sciatic nerve. Extra measurements at P56 illustrate mRNA expression in endoneurium $(\square)$ or peri/epineurium (O). Standard deviations were calculated from triplicate experiments. $(D)$ Western blots of endoneurium $(24 \mu \mathrm{g})$ or peri/epineurium $(16 \mu \mathrm{g})$ fractions of wild-type (wt) or Lpin1 mutant (fld/ fld) adult sciatic nerve, for depicted proteins. Note that the difference in detection of Apoe in wild-type samples compared with Figure 8B is due to shorter exposure time. Protein samples are derived from at least three animals per genotype. Bars: $A, B, 700 \mu \mathrm{m}$.

A

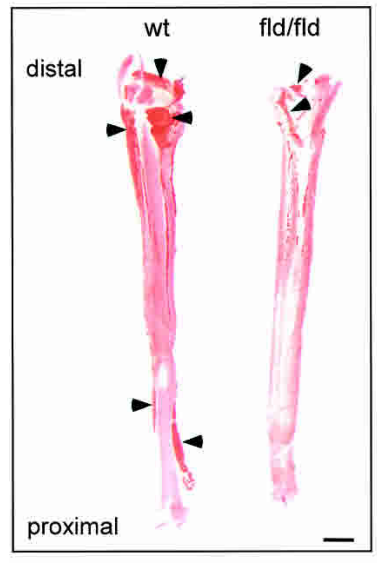

C

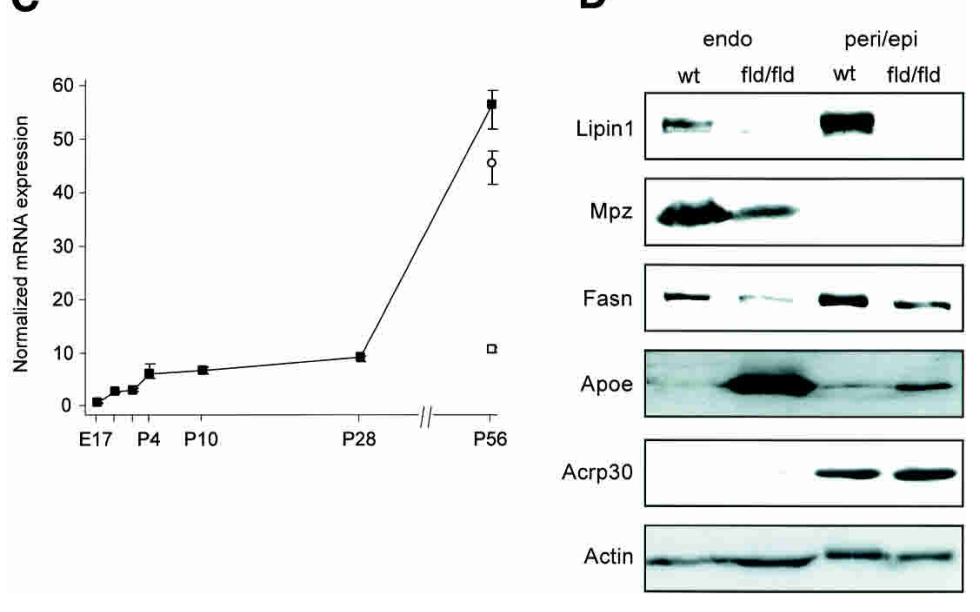

B

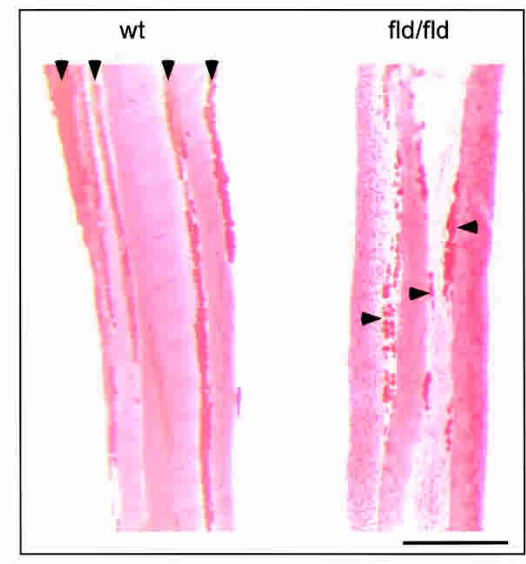

D structural proteins are delivered to the myelin sheath via membrane rafts enriched in cholesterol and galactolipids (Simons et al. 2000). The finding that genes involved in the biosynthesis of distinct components of the myelin sheath follow the same timecourse of expression during Schwann cell development may indicate coordinate transcriptional control by the same factor(s). We have identified SREBP-2 as a candidate transcriptional regulator of myelin lipid metabolism in the peripheral nerve. A large number of studies have demonstrated that SREBP-2 regulates lipid and cholesterol homeostasis in fat and liver (for review, see Horton et al. 2002). The fact that SREBP-2 expression in liver is induced by cholesterol depletion is in keeping with its expression in myelinating Schwann cells, whose synthesis of the cholesterolrich myelin membrane may lead to transient cytosolic cholesterol depletion (Fu et al. 1998), especially because nearly all accumulated cholesterol in the developing sciatic nerve is synthesized within the nerve (Jurevics and Morell 1994).

\section{Lipid metabolism in the mature peripheral nerve}

Our data demonstrate that adult Schwann cells express multiple genes involved in fatty acid metabolism (e.g.,
SREBP-1, Fasn, Scd1) and extracellular lipid transport (e.g., Apod and Apoe). SREBP-1 is known to be an important transcriptional regulator in liver for genes involved in fatty acid metabolism, including Fasn and Scd1 (Shimano et al. 1997; Horton et al. 1998), and is likely to have a similar function in the peripheral nerve. Apod and Apoe, which are required for the formation and transport of lipids via lipoproteins, probably function in lipid transport in the mouse peripheral nerve, as has been shown for Apoa-I in the chick (LeBlanc et al. 1989). Importantly, inactivation of the mouse Apoe gene affects the morphology of nonmyelinating Schwann cells and results in sensory nerve defects (Fullerton et al. 1998), which ties lipoprotein-mediated lipid transport in/from Schwann cells to the functioning of the mature nerve.

Direct evidence of the importance of local storage lipid metabolism to the maintenance of mature peripheral nerve functions comes from our analysis of Lpin1 mutant mice. In contrast to earlier reports (Peterfy et al. 2001), we demonstrate that Lpin1 mRNA and protein are expressed in both the endoneurium and peri/epineurium of the peripheral nerve, where they follow a "cluster 5" developmental expression profile. Mutation of Lpin1 affects both of these nerve compartments: It leads to a strong reduction in the adipose mass in the epineurium, 
and to the altered expression of proteins-including Fasn and Apoe-required for storage lipid metabolism in the endoneurium. This strongly suggests that the pronounced peripheral neuropathy evident in the mutants is a direct consequence of the absence of Lipin1, and the attendant dysregulation of storage lipid metabolism, in the nerve itself, and not a secondary effect from neonatal hypertriglyceridemia and fatty liver during the first 4 postnatal weeks (Langner et al. 1989, 1991).

Although adipose tissue in adult peripheral nerves has been noted previously (Sunderland 1945, 1965), its presence has for the most part been neglected (Thomas and Olsson 1984; Peters et al. 1991; Stolinski 1995). Adipocytes have been classically viewed as a storage depot for lipids, and as such may serve as a source of fatty acids for the endoneurium. It should be noted that fat also functions as an endocrine organ, through the production and secretion of adipokines that act on muscle, brain, and fat to regulate energy homeostasis and insulin action (Saltiel and Kahn 2001). Although the perineurium forms a diffusion barrier between the epineurium and the endoneurium, these two compartments are nonetheless connected by the vascular network of the peripheral nerve (Rechthand and Rapoport 1987). Our finding that two adipokines-Acrp30 and Resistin-are highly expressed in the epineurium suggests that this compartment may regulate lipid metabolism in Schwann cells and/or axons via supply of both fat metabolites and adipokines. Metabolic studies have demonstrated that both fatty acids and TAGs have a high turnover rate in the endoneurial compartment of the adult sciatic nerve, in contrast to cholesterol and galactolipids (Yao 1985). These fatty acids and storage lipids, delivered to the endoneurium through adipokine-mediated release from epineurial adipocytes, could readily function in energy metabolism for Schwann cells and/or axons.

\section{Implications for storage lipid metabolic disorders associated with peripheral neuropathy}

Our study may provide insight into human diseases producing demyelinating peripheral neuropathies associated with altered lipid metabolism. The Lpin1 mutant mouse described in this study is a model for human lipodystrophy (Langner et al. 1989, 1991; Reue et al. 2000; Peterfy et al. 2001), for which numerous cases with peripheral neuropathy have been reported (Fessel 1971; Tuck et al. 1983). Also, Refsum's disease is caused by mutation in phytanoyl-CoA hydroxylase (Pahx), which encodes for a peroxisomal enzyme regulating branched chain fatty acid oxidation (Jansen et al. 1997; Mihalik et al. 1997). We observe that Pahx is also expressed in the sciatic nerve, where it follows a "cluster 5" expression profile (see Supplemenatry Table S1). Furthermore, ongoing storage lipid metabolism in both the adipose epineurium and in Schwann cells may be related to the high prevalence $(-30 \%)$ of peripheral neuropathies in both insulin-dependent (type I) and independent (type II) diabetes mellitus (Tesfaye et al. 1996). Diabetic peripheral neuropathy (DPN) results in reduced conduction veloc- ity and demyelination of the peripheral nerve, but there is no general agreement as to whether the demyelination is the primary effect or whether it is a secondary effect of axonal damage. Several competing hypotheses have been advanced to explain the pathogenesis of DPN, including perturbed lipid metabolism, but its biological basis remains obscure (for review, see Sugimoto et al. 2000). Lipoprotein lipase (Lpl) activity in the sciatic nerve is reduced in diabetic rats and corrected by treatment with insulin, which links Lpl and fatty acids to the pathophysiology of diabetic neuropathy (Ferreira et al. 2002). Our demonstration that epineurial adipocytes are the main contributors of $L p l$ expression in the mature sciatic nerve suggests that production of Lpl by these cells promotes the hydrolysis of triglyceride-rich lipoproteins in the bloodstream, and thereby facilitates uptake of fatty acids by Schwann cells.

It should be noted that both Lpin1 mutation as well as diabetes cause demyelinating neuropathy in the PNS, whereas myelin in the CNS is generally not affected (Brownlee et al. 1986; Langner et al. 1991; Sugimoto et al. 2000). This is striking given the presence of adipocytes specifically in the peripheral nerve-these cells have not been detected apposed to axon tracts in the CNS. Indeed, the peripheral epineurium ends at the point at which peripheral nerves enter the CNS, where it becomes contiguous with the dura mater (Peters et al. 1991). We examined one "nerve-like" CNS axon tract in the mousethe optic nerve that connects the eyes to the brain - and observed that it does not contain an adipose epineurium (M.H.G. Verheijen, R. Chrast, P. Burrola, and G. Lemke, unpubl.).

In conclusion, our transcriptional analysis of developing sciatic nerve provides a newly comprehensive description of biological processes underlying Schwann cell maturation. Together with the identification of human homologs and their mapping positions for the highly differentially expressed genes, these data will contribute to the identification of new peripheral neuropathy disease genes. Most importantly, our findings provide important new functional insights into the regulation and role of lipid metabolism in the endoneurium and peri/epineurium of peripheral nerve, and may have important implications for the understanding and treatment of peripheral neuropathies associated with lipid metabolic disorders, including lipodystrophy and diabetes.

\section{Materials and methods}

\section{Mice}

ICR mice were obtained from Harlan Sprague Dawley. Female BALB/cByJ-Lpin ${ }^{+/+}$, BALB/cByJ-Lpin ${ }^{f l d /+}$, and BALB/cByJLpin $1^{\text {fld flf }}$ mice were obtained from The Jackson Laboratory. Throughout the text, mice of the Lpin $1^{\text {fld flfld }}$ phenotype are referred to as "Lpin1 mutant", and mice of both $\operatorname{Lpin} 1^{f l d /+}$ and Lpin $1^{+/+}$are referred to as "wild-type".

\section{Array hybridization}

Total RNA was isolated from sciatic nerves of at least 100 ICR mice for each developmental stage (E17, P0, P2, P4, P10, and 
P56) using TRIzol (Life Technologies), and subsequently purified by RNeasy kit (QIAGEN). Five micrograms of total RNA was labeled and hybridized to MG-U74Av2 chips (Affymetrix), as specified by the manufacturer. All labelings and hybridizations were done in duplicate.

\section{Data analysis}

Microarray data were analyzed using the Affymetrix Microarray Suite 4.0; per chip normalization was performed by scaling the Average Intensity of every chip to a Target Intensity of 2500. Subsequently, those genes that were called "expressed" and "differentially expressed" according to Affymetrix Microarray Suite 4.0 were selected using the software Bullfrog (Zapala et al. 2002). Next, data were imported into GeneSpring (Silicon Genetics), and per gene normalization was performed by using the median for each gene's expression values over all six time points (if expression was at least 0.01 , negative values were set to 0). Subsequently, the genes showing high differential expression $(p<0.01$ in ANOVA) were selected, and K-means cluster analyses were performed using Pearson correlation with GeneSpring. For each of the highly differentially expressed genes, the sequence was updated via BLAST search (http://www.ncbi.nlm. nih.gov/BLAST) when required, and biological function annotation was determined using the SOURCE database (http:// genome- www5.stanford. edu/cgi-bin/SMD/source/sourceSearch). When required, biological function annotation was created based on literature and according to the definitions of the Gene Ontology Consortium using the AmiGO database (http://www. godatabase.org/cgi-bin/go.cgi). Subsequently, genes were classified based on their biological function, and expression profiles of the different groups were analyzed using GeneSpring. Annotations for groups with putative outliers /with clearly distinct expression profile compared to other members of the same group) were re-examined. Human homologs and their map positions were determined by BLAST search (when required), and searching the SOURCE database. Critical regions for each peripheral neuropathy were obtained via the Inherited Peripheral Neuropathies Mutation Database (http://molgen-www.uia.ac. be/CMTMutations) and the Online Mendelian Inheritance in Man database (http://www.ncbi.nlm.nih.gov/entrez/query. fcgi? db=OMIM).To determine whether a gene maps to the critical regions for a peripheral neuropathy, we used a human map viewer (http://www.ncbi.nlm.nih.gov/mapview/map_search. cgi?). Because annotation of the human genome is a dynamic process, all data reflect the status of the genome as of July 2003.

\section{Microdissection of sciatic nerve}

Sciatic nerves from adult (P56) mice were placed in ice-cold phosphate-buffered saline ( $\mathrm{pH}$ 7.4). The perineurium, with the epineurium attached to it, was gently dissected away from the endoneurium along the whole length of the nerve, with the aid of fine forceps and a binocular dissecting microscope. In those cases where the nerve was heavily fasciculated and proper microdissection was therefore not possible, that part of the nerve was discarded.

\section{Quantitative (real-time) PCR}

cDNA was prepared using the SuperScript system (Life Technologies) starting with 250 ng of total RNA from the following samples: (1) E17, P0, P2, P4, P10, P28, and P56 unfractioned sciatic nerves; (2) dissected endoneurium form P56 sciatic nerves; and (3) dissected peri/epineurial part of P56 sciatic nerves. RNA was isolated from an independent pool of at least 10 animals, and was not used for array experiments. Relative quantification of expression of selected genes was performed using an ABI PRISM 7700 Sequence Detection System with SYBR green chemistry (Applied Biosystems) as described (http://docs.appliedbiosystems.com/pebiodocs/04303859.pdf).

Dissociation curve analysis was performed using Dissociation Curve 1.0 software (ABI) for each PCR reaction to detect and eliminate possible primer-dimer artifacts. Oligonucleotides (sequences available upon request) were selected to amplify a fragment containing sequences from two adjacent exons in order to avoid contaminating genomic DNA amplification. To standardize the amount of cDNA in each reaction, we measured the amount of the ubiquitin-conjugating enzyme Ube2l3 (GB\#: NM_009456), which showed no variation in expression in the sciatic nerve between E17 and P56 as detected by array experiments, and as was confirmed by independent Q-PCR measurements (data not shown).

\section{In situ hybridization}

Expression patterns of selected genes were analyzed by in situ hybridization with ${ }^{33} \mathrm{P}$-radiolabeled riboprobes using EST clones obtained from ResGen (Invitrogen; see Supplementary Table S6), as described (Zhadanov et al. 1995). Dissected sciatic nerves were immersion-fixed in $4 \%$ paraformaldehyde/PBS overnight at $4{ }^{\circ} \mathrm{C}$, followed by overnight infiltration with $20 \%$ sucrose/PBS. Cryoprotected tissues were then embedded in OCT medium (Miles). Hybridization was performed with $6-\mu \mathrm{m}$ longitudinal frozen sections of adult (P56) sciatic nerves. Control hybridizations with sense strand-labeled riboprobes gave no significant signals for all selected genes (data not shown).

\section{Western blotting}

Total and/or microdissected fractions of sciatic nerves were taken up in liquid nitrogen and thawed using boiling lysis buffer (BLB; $10 \mathrm{mM}$ Tris- $\mathrm{HCl}$ at $\mathrm{pH} 7.4,1 \%$ SDS, $1 \mathrm{mM}$ sodium vanadate, and Complete protease inhibitor cocktail; Roche). After thawing, extra protease inhibitors were added and the nerves were homogenized using a dounce and a polytron. Subsequently, lysates were centrifuged and the protein concentration of the supernatant was measured using a Pierce BCA protein assay kit. After SDS-PAGE, proteins were blotted to Hybond-P PVDF membrane and incubated with appropriate primary antibodies: rabbit anti-Lipin [provided by Dr. J.C. Lawrence Jr. (University of Virginia School of Medicine, Charlottesville, VA)] was used at $2 \mu \mathrm{g} / \mathrm{mL}$, mouse anti-Mpz monoclonal antibody P07 [provided by Dr. J.J. Archelos (Karl-Franzens-Universitat, Graz, Austria)] was used at a dilution of 1:10,000, rabbit anti-Acrp30 [provided by Dr. H. Lodish (Whitehead Institute for Biomedical Research, Cambridge, MA)] was used at 1:250, mouse monoclonals against Fasn and Thrsp (BD Biosciences) were used at 1:250, rabbit-anti Apoe (Calbiochem) was used at 1:2000, and mouse monoclonal against actin (Oncogene) was used at 1:5000. Subsequently, the blots were incubated with peroxidase-labeled secondary antibody, followed by ECL.

\section{Immunohistochemistry and histology}

To analyze the expression of SREBP-1, we blocked 6- $\mu \mathrm{m}$ crosssections of immersion-fixed (4\% paraformaldehyde/PBS overnight at $4^{\circ} \mathrm{C}$ ) adult (P56) sciatic nerves in $15 \%$ NDS/0.1\% TritonX in PBS for $1 \mathrm{~h}$ before incubation with rabbit anti-mouse SREBP-1 [provided by Dr. H. Shimano, (University of Tsukuba, Tsukuba, Ibaraki, Japan)] at a dilution of 1 to 50 together with 
mouse anti-pig Neurofilament 160 (Sigma) at a dilution of 1 to 200. Slides were subsequently incubated with Cy3-conjugated donkey anti-rabbit IgG (Jackson Immunoresearch Labs) together with Alexa Fluor 488-conjugated goat anti-mouse IgG (Molecular Probes), and staining was completed using a DAPI-Vectashield mounting medium (Vector Laboratories).

Immersion-fixed $(4 \%$ paraformaldehyde/PBS overnight at $4^{\circ} \mathrm{C}$ ) adult (P56) sciatic nerves were stained with Mayer's Hematoxylin (on 6- $\mu \mathrm{m}$ frozen sections) for $5 \mathrm{~min}$ or Oil Red O (on intact nerves) for $10 \mathrm{~min}$, followed by washing with tapwater for $5 \mathrm{~min}$. Hematoxylin-stained nerves sections were subsequently incubated in Eosin Y (Alcoholic) for 1 min, washed with 100\% ETOH for $1 \mathrm{~min}$, followed by a 5 -min incubation with Histoclear (National Diagnostics). All incubations were done at room temperature. Sections were mounted using Permount (Fisher).

\section{Acknowledgments}

We thank Dan Syroid for advice and help with tissue isolations, and Joe Hash for technical assistance. We thank J.C. Lawrence Jr., H. Shimano, J.J. Archelos, and H. Lodish for generous supply of antibodies. This work was supported by a stipend of the Ter Meulen Fund, Royal Netherlands Academy of Arts and Sciences, and a long-term fellowship of the Human Frontier Science Program (to M.H.G.V); by a postdoctoral fellowship from the Swiss National Science Foundation (to R.C., grant 823A064660); and by grants from the NIH (to G.L.).

The publication costs of this article were defrayed in part by payment of page charges. This article must therefore be hereby marked "advertisement" in accordance with 18 USC section 1734 solely to indicate this fact.

\section{References}

Baxter, R.V., Ben Othmane, K., Rochelle, J.M., Stajich, J.E., Hulette, C., Dew-Knight, S., Hentati, F., Ben Hamida, M., Bel, S., Stenger, J.E., et al. 2002. Ganglioside-induced differentiation-associated protein-1 is mutant in Charcot-Marie-Tooth disease type 4A/8q21. Nat. Genet. 30: 21-22.

Bennett, C.L. and Chance, P.F. 2001. Molecular pathogenesis of hereditary motor, sensory and autonomic neuropathies. Curr. Opin. Neurol. 14: 621-627.

Bermingham Jr., J.R., Scherer, S.S., O'Connell, S., Arroyo, E., Kalla, K.A., Powell, F.L., and Rosenfeld, M.G. 1996. Tst-1/ Oct-6/SCIP regulates a unique step in peripheral myelination and is required for normal respiration. Genes \& Dev. 10: $1751-1762$.

Brockes, J.P., Fields, K.L., and Raff, M.C. 1979. Studies on cultured rat Schwann cells. I. Establishment of purified populations from cultures of peripheral nerve. Brain Res. 165: 105-118.

Brownlee, M., Vlassara, H., and Cerami, A. 1986. Trapped immunoglobulins on peripheral nerve myelin from patients with diabetes mellitus. Diabetes 35: 999-1003.

Cuesta, A., Pedrola, L., Sevilla, T., Garcia-Planells, J., Chumillas, M.J., Mayordomo, F., LeGuern, E., Marin, I., Vilchez, J.J., and Palau, F. 2002. The gene encoding ganglioside-induced differentiation-associated protein 1 is mutated in axonal Charcot-Marie-Tooth type 4A disease. Nat. Genet. 30: 2225.

Einheber, S., Milner, T.A., Giancotti, F., and Salzer, J.L. 1993. Axonal regulation of Schwann cell integrin expression suggests a role for $\alpha 6 \beta 4$ in myelination. J. Cell Biol. 123: 12231236.
Feltri, M.L., Scherer, S.S., Nemni, R., Kamholz, J., Vogelbacker, H., Scott, M.O., Canal, N., Quaranta, V., and Wrabetz, L. 1994. $\beta 4$ integrin expression in myelinating Schwann cells is polarized, developmentally regulated and axonally dependent. Development 120: 1287-1301.

Ferreira, L.D., Huey, P.U., Pulford, B.E., Ishii, D.N., and Eckel, R.H. 2002. Sciatic nerve lipoprotein lipase is reduced in streptozotocin-induced diabetes and corrected by insulin. Endocrinology 143: 1213-1217.

Fessel, W.J. 1971. Fat disorders and peripheral neuropathy. Brain 94: 531-540.

Fu, Q., Goodrum, J.F., Hayes, C., Hostettler, J.D., Toews, A.D., and Morell, P. 1998. Control of cholesterol biosynthesis in Schwann cells. J. Neurochem 71: 549-555.

Fullerton, S.M., Strittmatter, W.J., and Matthew, W.D. 1998. Peripheral sensory nerve defects in apolipoprotein E knockout mice. Exp. Neurol. 153: 156-163.

Garbay, B., Boiron-Sargueil, F., Shy, M., Chbihi, T., Jiang, H., Kamholz, J., and Cassagne, C. 1998. Regulation of oleoylCoA synthesis in the peripheral nervous system: Demonstration of a link with myelin synthesis. I. Neurochem. 71: 1719-1726.

Garbay, B., Heape, A.M., Sargueil, F., and Cassagne, C. 2000 Myelin synthesis in the peripheral nervous system. Prog. Neurobiol. 61: 267-304.

Garbern, J.Y., Cambi, F., Tang, X.M., Sima, A.A., Vallat, J.M., Bosch, E.P., Lewis, R., Shy, M., Sohi, J., Kraft, G., et al. 1997. Proteolipid protein is necessary in peripheral as well as central myelin. Neuron 19: 205-218.

Horton, J.D., Shimomura, I., Brown, M.S., Hammer, R.E., Goldstein, J.L., and Shimano, H. 1998. Activation of cholesterol synthesis in preference to fatty acid synthesis in liver and adipose tissue of transgenic mice overproducing sterol regulatory element-binding protein-2. J. Clin. Invest. 101: 23312339.

Horton, J.D., Goldstein, J.L., and Brown, M.S. 2002. SREBPs: Activators of the complete program of cholesterol and fatty acid synthesis in the liver. J. Clin. Invest. 109: 1125-1131.

Jaegle, M., Mandemakers, W., Broos, L., Zwart, R., Karis, A., Visser, P., Grosveld, F., and Meijer, D. 1996. The POU factor Oct-6 and Schwann cell differentiation. Science 273: 507510.

Jansen, G.A., Ofman, R., Ferdinandusse, S., Ijlst, L., Muijsers, A.O., Skjeldal, O.H., Stokke, O., Jakobs, C., Besley, G.T., Wraith, J.E., et al. 1997. Refsum disease is caused by mutations in the phytanoyl-CoA hydroxylase gene. Nat. Genet. 17: 190-193.

Jessen, K.R. and Mirsky, R. 1999. Schwann cells and their precursors emerge as major regulators of nerve development. Trends Neurosci. 22: 402-410.

Jessen, K.R., Mirsky, R., and Morgan, L. 1987. Myelinated, but not unmyelinated axons, reversibly downregulate N-CAM in Schwann cells. J. Neurocytol. 16: 681-688.

Jurevics, H.A. and Morell, P. 1994. Sources of cholesterol for kidney and nerve during development. J. Lipid Res. 35: 112120

Keegan, B.M. and Noseworthy, J.H. 2002. Multiple sclerosis. Annu. Rev. Med. 53: 285-302.

Langner, C.A., Birkenmeier, E.H., Ben-Zeev, O., Schotz, M.C., Sweet, H.O., Davisson, M.T., and Gordon, J.I. 1989. The fatty liver dystrophy (fld) mutation. A new mutant mouse with a developmental abnormality in triglyceride metabolism and associated tissue-specific defects in lipoprotein lipase and hepatic lipase activities. J. Biol Chem. 264: 79948003.

Langner, C.A., Birkenmeier, E.H., Roth, K.A., Bronson, R.T., 
and Gordon, J.I. 1991. Characterization of the peripheral neuropathy in neonatal and adult mice that are homozygous for the fatty liver dystrophy (fld) mutation. J. Biol Chem. 266: 11955-11964.

LeBlanc, A.C., Foldvari, M., Spencer, D.F., Breckenridge, W.C., Fenwick, R.G., Williams, D.L., and Mezei, C. 1989. The apolipoprotein A-I gene is actively expressed in the rapidly myelinating avian peripheral nerve. J. Cell Biol. 109: 12451256.

Low, P.A. 1976. Hereditary hypertrophic neuropathy in the trembler mouse. Part 2. Histopathological studies: Electron microscopy. J. Neurol. Sci. 30: 343-368.

Martyn, C.N. and Hughes, R.A. 1997. Epidemiology of peripheral neuropathy. J. Neurol. Neurosurg. Psychiatry 62: 310318.

Mihalik, S.J., Morrell, J.C., Kim, D., Sacksteder, K.A., Watkins, P.A., and Gould, S.J. 1997. Identification of PAHX, a Refsum disease gene. Nat. Genet. 17: 185-189.

Mohr, E. 1999. Subcellular RNA compartmentalization. Prog. Neurobiol. 57: 507-525.

Monuki, E.S., Kuhn, R., Weinmaster, G., Trapp, B.D., and Lemke, G. 1990. Expression and activity of the POU transcription factor SCIP. Science 249: 1300-1303.

Nagarajan, R., Le, N., Mahoney, H., Araki, T., and Milbrandt, J. 2002. Deciphering peripheral nerve myelination by using Schwann cell expression profiling. Proc. Natl. Acad. Sci. 99: 8998-9003.

Nakao, J., Shinoda, J., Nakai, Y., Murase, S., and Uyemura, K. 1997. Apoptosis regulates the number of Schwann cells at the premyelinating stage. J. Neurochem. 68: 1853-1862.

Peterfy, M., Phan, J., Xu, P., and Reue, K. 2001. Lipodystrophy in the fld mouse results from mutation of a new gene encoding a nuclear protein, lipin. Nat. Genet. 27: 121-124.

Peters, A., Palay, S.L., and Webster, H.D.F. 1991. The fine structure of the nervous system: Neurons and their supporting cells, 3rd ed. Oxford University Press, New York.

Rechthand, E. and Rapoport, S.I. 1987. Regulation of the microenvironment of peripheral nerve: Role of the blood-nerve barrier. Prog. Neurobiol. 28: 303-343.

Reue, K., Xu, P., Wang, X.P., and Slavin, B.G. 2000. Adipose tissue deficiency, glucose intolerance, and increased atherosclerosis result from mutation in the mouse fatty liver dystrophy (fld) gene. J. Lipid Res. 41: 1067-1076.

Rust Jr., R.S., Carter, J.G., Martin, D., Nerbonne, J.M., Lampe, P.A., Pusateri, M.E., and Lowry, O.H. 1991. Enzyme levels in cultured astrocytes, oligodendrocytes, and Schwann cells, and neurons from the cerebral cortex and superior cervical ganglia of the rat. Neurochem. Res. 16: 991-999.

Saltiel, A.R. and Kahn, C.R. 2001. Insulin signalling and the regulation of glucose and lipid metabolism. Nature 414: 799-806.

Shimano, H., Shimomura, I., Hammer, R.E., Herz, J., Goldstein, J.L., Brown, M.S., and Horton, J.D. 1997. Elevated levels of SREBP-2 and cholesterol synthesis in livers of mice homozygous for a targeted disruption of the SREBP-1 gene. J. Clin. Invest. 100: 2115-2124.

Simons, M., Kramer, E.M., Thiele, C., Stoffel, W., and Trotter, J. 2000. Assembly of myelin by association of proteolipid protein with cholesterol- and galactosylceramide-rich membrane domains. J. Cell Biol. 151: 143-154.

Skre, H. 1974. Genetic and clinical aspects of Charcot-MarieTooth's disease. Clin. Genet. 6: 98-118.

Stewart, H.J., Morgan, L., Jessen, K.R., and Mirsky, R. 1993. Changes in DNA synthesis rate in the Schwann cell lineage in vivo are correlated with the precursor-Schwann cell transition and myelination. Eu.r T. Neurosci. 5: 1136-1144.
Stolinski, C. 1995. Structure and composition of the outer connective tissue sheaths of peripheral nerve. J. Anat. 186 (Pt 1): $123-130$.

Sugimoto, K., Murakawa, Y., and Sima, A.A. 2000. Diabetic neuropathy-A continuing enigma. Diabetes Metab. Res. Rev. 16: 408-433.

Sunderland, S. 1945. The adipose tissue of peripheral nerves. Brain 68: 118-124.

-1965. The connective tissues of peripheral nerves. Brain 88: $841-854$.

Swiatek, P.J. and Gridley, T. 1993. Perinatal lethality and defects in hindbrain development in mice homozygous for a targeted mutation of the zinc finger gene Krox20. Genes \& Dev. 7: 2071-2084.

Syroid, D.E., Maycox, P.R., Burrola, P.G., Liu, N., Wen, D., Lee, K.F., Lemke, G., and Kilpatrick, T.J. 1996. Cell death in the Schwann cell lineage and its regulation by neuregulin. Proc. Nat1. Acad. Sci. 93: 9229-9234.

Tesfaye, S., Stevens, L.K., Stephenson, J.M., Fuller, J.H., Plater, M., Ionescu-Tirgoviste, C., Nuber, A., Pozza, G., and Ward, J.D. 1996. Prevalence of diabetic peripheral neuropathy and its relation to glycaemic control and potential risk factors: The EURODIAB IDDM Complications Study. Diabetologia 39: $1377-1384$.

Thomas, P.K. and Olsson, Y. 1984. Microscopic anatomy and function of the connective tissue components of peripheral nerve In: Peripheral Neuropathy, Vol. I, 2nd ed. (eds. P.J. Dyck et al.), pp. 97-120. W.B. Saunders Company, Philadelphia.

Topilko, P., Schneider-Maunoury, S., Levi, G., Baron-Van Evercooren, A., Chennoufi, A.B., Seitanidou, T., Babinet, C., and Charnay, P. 1994. Krox-20 controls myelination in the peripheral nervous system. Nature 371: 796-799.

Tuck, R.R., McLeod, J.G., Basten, A., Ellis, D., and Kirwan, P.D. 1983. Total lipodystrophy—a report of a case with peripheral neuropathy and glomerulonephritis. Aust. N Z I Med. 13: 65-69.

Vance, J.M. 2000. The many faces of Charcot-Marie-Tooth disease. Arch. Neurol. 57: 638-640.

Webster, H.D. 1971. The geometry of peripheral myelin sheaths during their formation and growth in rat sciatic nerves. $J$. Cell Biol. 48: 348-367.

Yao, J.K. 1985. Metabolic turnover of fatty acids and acylglycerols in rat sciatic nerve. J. Neurochem. 45: 589-595.

Zapala, M.A., Lockhart, D.J., Pankratz, D.G., Garcia, A.J., and Barlow, C. 2002. Software and methods for oligonucleotide and cDNA array data analysis. Genome Biol. 3: SOFTWARE0001.1-SOFTWARE0001.9.

Zhadanov, A.B., Bertuzzi, S., Taira, M., Dawid, I.B., and Westphal, H. 1995. Expression pattern of the murine LIM class homeobox gene Lhx3 in subsets of neural and neuroendocrine tissues. Dev. Dyn. 202: 354-364.

Zorick, T.S. and Lemke, G. 1996. Schwann cell differentiation. Curr. Opin. Cell Biol. 8: 870-876.

Zorick, T.S., Syroid, D.E., Arroyo, E., Scherer, S.S., and Lemke, G. 1996. The transcription factors SCIP and Krox-20 mark distinct stages and cell fates in Schwann cell differentiation. Mol. Cell Neurosci. 8: 129-145.

Zorick, T.S., Syroid, D.E., Brown, A., Gridley, T., and Lemke, G. 1999. Krox-20 controls SCIP expression, cell cycle exit and susceptibility to apoptosis in developing myelinating Schwann cells. Development 126: 1397-1406. 


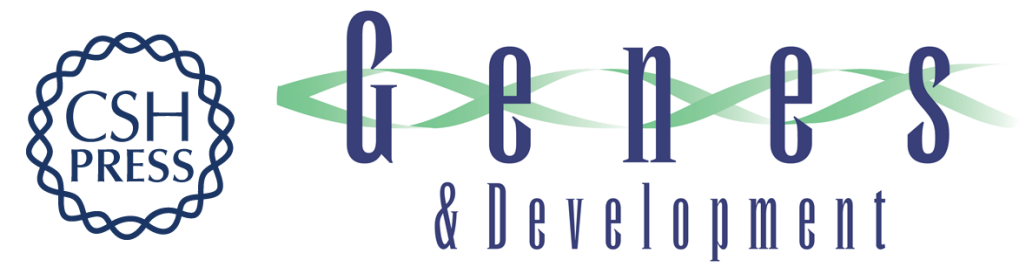

\section{Local regulation of fat metabolism in peripheral nerves}

Mark H.G. Verheijen, Roman Chrast, Patrick Burrola, et al.

Genes Dev. 2003, 17:

Access the most recent version at doi:10.1101/gad.1116203

Supplemental

Material

References

This article cites 59 articles, 18 of which can be accessed free at:

http://genesdev.cshlp.org/content/17/19/2450.full.html\#ref-list-1

\section{License}

Email Alerting Service

http://genesdev.cshlp.org/content/suppl/2003/10/02/17.19.2450.DC1 right corner of the article or click here.

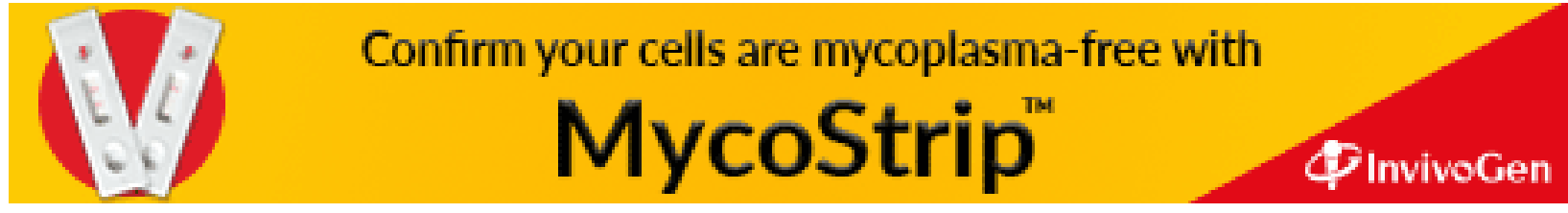

